\title{
A Large Central Bronchopleural Fistula Closed by Bronchoscopic Administration of Recombinant Bovine Basic Fibroblast Growth Factor: A Case Report
}

\author{
Shuliang Guo Yang Bai Yishi Li Tao Chen
}

Department of Respiratory and Critical Care Medicine, The First Affiliated Hospital of Chongqing Medical University, Chongqing, PR China

\section{Established Facts}

- Bronchoscopic treatment could be applied as an adjuvant or complementary procedure to surgery for the closure of bronchopleural fistula (BPF), especially in those severely ill patients.

- The recombinant bovine basic fibroblast growth factor, together with open thoracotomy, has been used to close BPFs about 4-25 $\mathrm{mm}$ in diameter.

\section{Novel Insights}

- The bronchoscopic treatment with recombinant bovine basic fibroblast growth factor is a potentially cost-effective method for the closure of central bronchopleural fistula surrounded by mediastinal tissue.

\section{Keywords}

Bronchopleural fistula · Bronchoscopic treatment - Basic

fibroblast growth factor

\section{Abstract}

A large central bronchopleural fistula (BPF) surrounded by mediastinal tissue was successfully closed by local administration of recombinant bovine basic fibroblast growth factor (rbFGF) using the bronchoscope. No complications were observed during and after this bronchoscopic treatment. This is the first report of the bronchoscopic treatment of a large central BPF by the local spray of rbFGF. The bronchoscopic

karger@karger.com www.karger.com/res

Karger $\stackrel{\text { ' }}{5}$

GOPEN ACCESS
(C) 2021 The Author(s)

Published by S. Karger AG, Basel

This is an Open Access article licensed under the Creative Commons Attribution-NonCommercial-4.0 International License (CC BY-NC) (http://www.karger.com/Services/OpenAccessLicense), applicable to the online version of the article only. Usage and distribution for commercial purposes requires written permission. treatment with rbFGF is a potentially cost-effective method for central BPF surrounded by mediastinal tissue.

(c) 2021 The Author(s)
Published by S. Karger AG, Basel

\section{Introduction}

Bronchopleural fistula (BPF) is a pathological channel between the bronchial tree and pleural space, divided into central and peripheral types. The central BPF usually results from lung resection surgery, with an inci-

Shuliang Guo and Yang Bai contributed equally to this article.
Correspondence to:

Shuliang Guo, guos1999@sina.com 
dence ranging from 4.5 to $20 \%$ after pneumonectomy and $0.5-1 \%$ after lobectomy, respectively, and BPF-related mortality ranges from 16.0 to $71.2 \%[1,2]$. The right side pneumonectomy is associated with a higher risk for BPF [3]. Closure of central BPF by either video-assisted thoracoscopic surgery or open thoracotomy is recommended if the clinical situation allows a major reoperation. The success rate of BPF closure with surgery has been reported to be over $85 \%$ in those patients $[4,5]$. Various bronchoscopic treatments have been reported for the closure of BPF in small studies, case reports, and expert consensuses, such as adhesive tissue and fibrin glue [6], sclerosing agent [7], one-way endobronchial valve $[8,9]$, ventricular septal defect occluder [10], covered expandable metallic stent [11], endobronchial Watanabe spigot $[12,13]$, and vascular occlusion coil [14]. Although there are no randomized controlled trials to study the efficacy and safety between surgical and bronchoscopic treatment for the closure of postoperative central BPF, the bronchoscopic treatment seems to be a comfortable, safe, well-tolerated, and cost-effective procedure. Bronchoscopic treatment could be applied as an adjuvant or complementary procedure to surgery, especially in those severely ill patients [15].

We report the successful closure of a large central BPF surrounded by mediastinal tissue after right upper lobectomy by the local administration of recombinant bovine basic fibroblast growth factor (rbFGF) applied directly under flexible bronchoscopic observation. Bronchoscopic administration of rbFGF might be an alternative procedure for the closure of postoperative central BPF surrounded by mediastinal tissue.

\section{Case Report}

A 52-year-old man complained of fever and air leakage from the chest tube 14 days after right upper lobectomy for adenocarcinoma of the lung was referred to our hospital. A large central BPF (Fig. 1a) surrounded by mediastinal tissue (Fig. 1b) was detected by computed tomography. The bronchoscope confirmed the intracavitary lumen with a diameter of $14 \mathrm{~mm}$ in the right middle bronchus (Fig. 1c). Primary treatment modalities for the management of such a large central BPF include surgery [4], ventricular septal defect occluder [10], and Y-type covered metallic expandable stent [11]. The surgeons did not recommend the primary surgical repair of this unstable large BPF. The ventricular septal defect occluder might not suit the BPF with a long tract. And the patient refused the Y-type covered metallic expandable stent due to financial burden and complications such as stent restenosis, intolerance of stenting, retention of mucus, or pneumonia. rbFGF is a multipotential glycoprotein known to stimulate angiogenesis and fibroblast proliferation and is widely used to treat wounds and ulcers
$[16,17]$. The rbFGF, together with open thoracotomy, has been used to close BPFs about 4-25 $\mathrm{mm}$ in diameters [18-20]. The rbFGF might be an effective, well-tolerated, and low-cost procedure for the closure of BPF. As there was no evidence of recurrence or residual tumor, we proposed the repetition of rbFGF could promote epithelialization and granulation tissue formation for the closure of BPF. The rbFGF (Beifuji Spray, Essex Bio-Pharmaceutical Co., Ltd; $262.5 \mathrm{IU} / \mathrm{cm}^{2}$ and 6,000 IU/time) was sprayed into and around the fistula through the $\mathrm{V}$-System single-use cannula (PR-V416Q, Olympus Co., Ltd.). The fistula was partially covered by epithelium and granulation tissue 1 week after the first spraying of rbFGF (Fig. 2a) and then healed with a constrictive scar at the bronchial surface (Fig. 2b) 1 week after the second spray, which was confirmed by computed tomography (Fig. 2c). No complications were observed during and after this bronchoscopic treatment. The chest tube was removed, and then the patient was discharged.

\section{Discussion}

This case is the first to close a large central BPF surrounded by mediastinal tissue through spraying rbFGF into and around the fistula under the fiberoptic bronchoscope. rbFGF induced scar formation over a short period in this case. This result was consistent with those reporting rbFGF on the treatment of gastric ulcers, in which accelerated healing of ulcers was observed soon after oral administration of rbFGF [21-23]. The histological examination of ulcers in animals treated with rbFGF showed prominent vascularization and dense granulation tissue in the ulcer bed [22]. Wound healing is a complex process involving inflammation, granulation tissue formation, reepithelialization, extracellular matrix formation, and remodeling [24]. The rbFGF can promote the proliferation of endothelial cells and then its physical organization into tube-like structures, thus promoting angiogenesis, indicating its role in the closure of fistula [25]. Indications for rbFGF are burns (including superficial II, deep II, and granulation wounds), chronic wounds (including chronic ulcer), and fresh wounds (traumatic, donor site wound, and surgical wound) [26]. The rbFGF, together with open thoracotomy, has been used to close BPFs about $4-25 \mathrm{~mm}$ in diameters [18-20]. Topical rbFGF treatments were well-tolerated, and no drug-related adverse events were reported for now [18-23]. Another advantage of rbFGF is its low price and commercial availability. Endoscopic treatment with rbFGF spraying could be an adjuvant or complementary procedure to surgery for the closure of BPF.

Surgical resection and closure of the fistula might induce the patient's great stress because of the financial burden and an increased risk of surgical failure. Flexible 

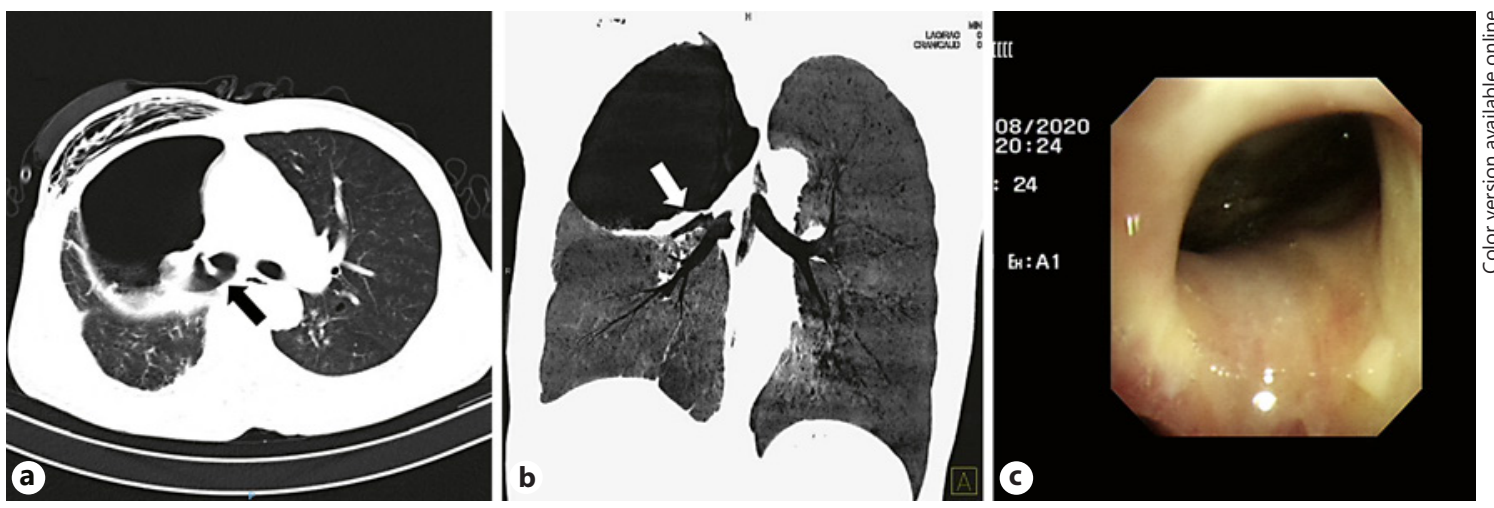

Fig. 1. a Chest CT demonstrated a large central BPF (black arrow) localized in the right middle bronchus. b The axis CT showed the central BPF surrounded by mediastinal tissue (white arrow). c The bronchoscopic view of the large central BPF with a diameter of $14 \mathrm{~mm}$. CT, computed tomography; BPF, bronchopleural fistula.
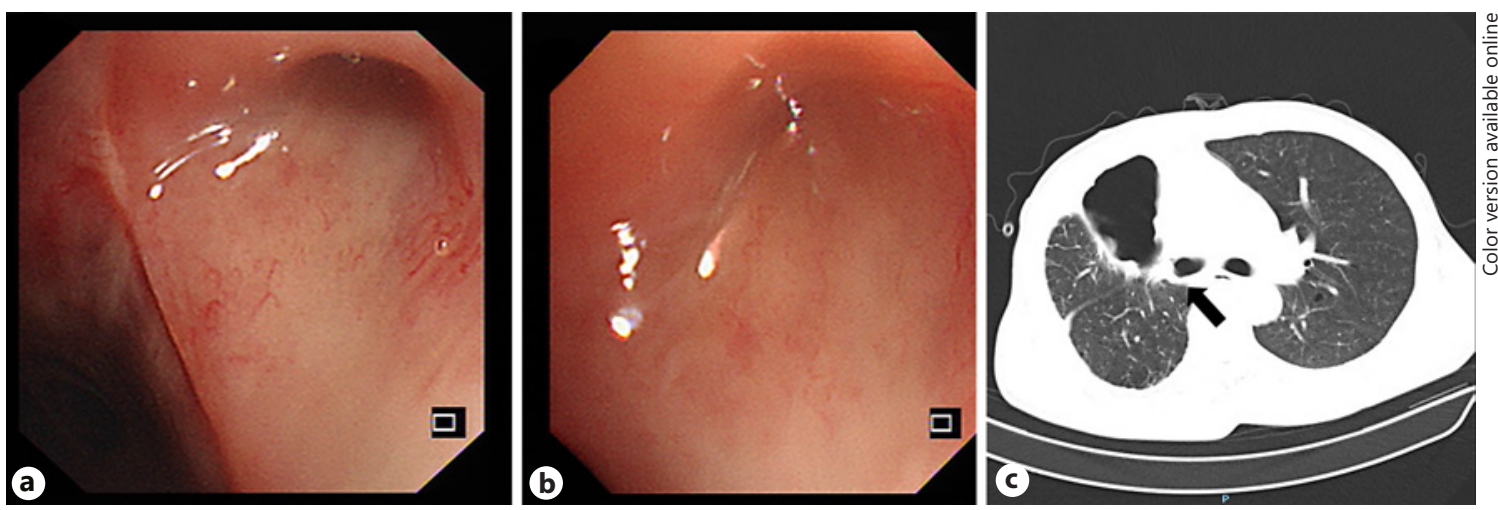

Fig. 2. a The bronchoscopic view of the large central BPF partially covered by epithelium and granulation tissue. b The bronchoscopic view of the large central BPF sealed and covered by scar tissue. c Chest CT confirmed the closure of the large central BPF (black arrow). CT, computed tomography; BPF, bronchopleural fistula.

bronchoscopy has evolved from diagnostic to therapeutic modalities in the management of BPF, enabling evaluation of the stump, visualization of the fistula location and size, and the decision of treatment strategy simultaneously. In one of the most extensive series (150 patients), improvement or resolution of BPF occurred in $83 \%$ of patients treated bronchoscopically [13]. And a minor BPF without empyema was treated successfully using bronchoscopy with the administration of OK-432, rbFGF, and fibrin glue sealant [27]. The rbFGF could increase mesenchymal stem cells' migratory activity by activating the Akt/protein kinase B pathway [28]. In addition to rbFGF, mesenchymal stem cells have been injected submucosally for the closure of BPF through a flexible bronchoscope [29]. However, issues in the preparation of mesenchymal stem cells, such as donor heterogeneity, ex vivo expansion, immunogenicity, and cryopreservation, limit its clinical application [30]. Endoscopic sclerotherapy by submucosal injection of absolute ethanol or silver nitrate around the fistula might not suit such a large BPF $[31,32]$.

The size of BPF seems to be an important predictive factor for the result of bronchoscopic treatment. BPFs $>8$ $\mathrm{mm}$ or large central BPFs are usually unsuitable for bronchoscopic treatment $[15,33]$. The bronchopleural air leak $>500 \mathrm{~mL} / \mathrm{breath}$ during mechanical ventilation is associated with high mortality and bronchoscopic treatment failure $[33,34]$. The successful treatment of large central BPF by the simple spray of rbFGF might also be due to the fistula being covered by the mediastinum in this case, reducing air leak and increasing the topical concentration of rbFGF. More clinical studies are needed to elucidate the endoscopic use of rbFGF in the management of BPF and the long-term effects concerning the evaluation of rbFGF tumorigenic potential [35]. 


\section{Conclusion}

We report a large central BPF surrounded by mediastinal tissue after the right upper lobectomy was successfully treated by spraying rbFGF into and around the fistula under the bronchoscope. The bronchoscopic treatment with rbFGF, a safe and cost-effective method, is worth trying in selected cases for the closure of postoperative central BPF surrounded by mediastinal tissue.

\section{Acknowledgement}

We wish to thank the timely care and proper management given by Ying Yuan for the patient.

\section{Statement of Ethics}

The research was conducted ethically in accordance with the World Medical Association Declaration of Helsinki. The patient provided written informed consent for publication of this case report and all the accompanying images.

\section{Conflict of Interest Statement}

The authors have no conflicts of interest to declare.

\section{Funding Sources}

The present study was funded by the National Science and Technology Major Project of China (2018ZX10302302003).

\section{Author Contributions}

Shuliang Guo designed and performed the administration of recombinant bovine basic fibroblast growth factor in and around the fistula under the fiberoptic bronchoscope. Yang Bai wrote and edited the manuscript. Yishi Li and Tao Chen reviewed the manuscript. All authors read and approved the final manuscript.

\section{References}

1 Li S, Fan J, Liu J, Zhou J, Ren Y, Shen C, et al. Neoadjuvant therapy and risk of bronchopleural fistula after lung cancer surgery: a systematic meta-analysis of 14,912 patients. Jpn J Clin Oncol. 2016;46(6):534-46.

2 Claes P, Cappoen D, Uythethofken C, Jacobs J, Mertens B, Mathys V, et al. 2,4-Dialkyl8,9,10,11-tetrahydrobenzo[g]pyrimido[4,5c] isoquinoline-1,3,7,12(2H,4H)-tetraones as new leads against mycobacterium tuberculosis. Eur J Med Chem. 2014;77:409-21.

3 Darling GE, Abdurahman A, Yi QL, Johnston $\mathrm{M}$, Waddell TK, Pierre A, et al. Risk of a right pneumonectomy: role of bronchopleural fistula. Ann Thorac Surg. 2005;79(2):433-7.

4 Puskas JD, Mathisen DJ, Grillo HC, Wain JC, Wright CD, Moncure AC. Treatment strategies for bronchopleural fistula. J Thorac Cardiovasc Surg. 1995;109(5):989-95; discussion 995-6.

5 Massera F, Robustellini M, Pona CD, Rossi G, Rizzi A, Rocco G. Predictors of successful closure of open window thoracostomy for postpneumonectomy empyema. Ann Thorac Surg. 2006;82(1):288-92.

6 Eng J, Sabanathan S. Successful closure of bronchopleural fistula with adhesive tissue. Case report. Scand J Thorac Cardiovasc Surg. 1990;24(2):157-9.

7 Boudaya MS, Smadhi H, Zribi H, Mohamed J, Ammar J, Mestiri T, et al. Conservative management of postoperative bronchopleural fistulas. J Thorac Cardiovasc Surg. 2013; 146(3):575-9.

8 Travaline JM, McKenna RJ Jr, De Giacomo T, Venuta F, Hazelrigg SR, Boomer $\mathrm{M}$, et al.
Treatment of persistent pulmonary air leaks using endobronchial valves. Chest. 2009; 136(2):355-60.

9 Gillespie CT, Sterman DH, Cerfolio RJ, Nader D, Mulligan MS, Mularski RA, et al. Endobronchial valve treatment for prolonged air leaks of the lung: a case series. Ann Thorac Surg. 2011;91(1):270-3.

10 Fruchter O, El Raouf BA, Abdel-Rahman N, Saute M, Bruckheimer E, Kramer MR. Efficacy of bronchoscopic closure of a bronchopleural fistula with amplatzer devices: longterm follow-up. Respiration. 2014;87(3):22733.

11 Han X, Yin M, Li L, Zhu M, Ren K, Qi Y, et al. Customized airway stenting for bronchopleural fistula after pulmonary resection by interventional technique: single-center study of 148 consecutive patients. Surg Endosc. 2018; 32(10):4116-24.

12 Watanabe Y, Matsuo K, Tamaoki A, Komoto R, Hiraki S. Bronchial occlusion with endobronchial watanabe spigot. J Bronchol. 2003; 10(4):264-7.

13 Zhang HT, Xie YH, Gu X, Li WP, Zeng YM, Li SY, et al. Management of persistent air leaks using endobronchial autologous blood patch and spigot occlusion: a multicentre randomized controlled trial in China. Respiration. 2019;97(5):436-43.

14 Sivrikoz CM, Kaya T, Tulay CM, Ak I, Bilir A, Döner E. Effective approach for the treatment of bronchopleural fistula: application of endovascular metallic ring-shaped coil in combination with fibrin glue. Ann Thorac Surg. 2007;83(6):2199-201.
15 Lois M, Noppen M. Bronchopleural fistulas: an overview of the problem with special focus on endoscopic management. Chest. 2005; 128(6):3955-65.

16 Zhang X, Kang X, Jin L, Bai J, Liu W, Wang Z. Stimulation of wound healing using bioinspired hydrogels with basic fibroblast growth factor (bFGF). Int J Nanomedicine. 2018;13: 3897-906.

17 Abdelhakim M, Lin X, Ogawa R. The Japanese experience with basic fibroblast growth factor in cutaneous wound management and scar prevention: a systematic review of clini$\mathrm{cal}$ and biological aspects. Dermatol Ther. 2020;10(4):569-87.

18 Okuda M, Yokomise H, Tarumi S, Huang CL. Non-surgical closure of post-pneumonectomy empyema with bronchopleural fistula after open window thoracotomy using basic fibroblast growth factor. Interact Cardiovasc Thorac Surg. 2009;9(5):916-8.

19 Tanaka S, Yajima T, Mogi A, Kuwano H. Successful management of a large bronchopleural fistula after lobectomy: report of a case. Surg Today. 2011;41(12):1661-4.

20 Goto T, Tsuchida M, Koike T, Sato S, Kitahara A, Nakamura A. Negative-pressure wound therapy with basic fibroblast growth factor splay for empyema with bronchial fistula after lung resection: a case. Heart Lung Circ. 2018; 27:S558-9.

21 Konturek SJ, Brzozowski T, Majka J, Szlachcic A, Bielanski W, Stachura J, et al. Fibroblast growth factor in gastroprotection and ulcer healing: interaction with sucralfate. Gut. 1993;34(7):881-7. 
22 Szabo S, Folkman J, Vattay P, Morales RE, Pinkus GS, Kato K. Accelerated healing of duodenal ulcers by oral administration of a mutein of basic fibroblast growth factor in rats. Gastroenterology. 1994;106(4):1106-11.

23 Pohle T, Shahin M, Domschke W, Konturek JW. Effect of basic fibroblast growth factor on gastric ulcer healing and its own mRNA expression. Aliment Pharmacol Ther. 1999; 13(11):1543-51.

24 Barrientos S, Stojadinovic O, Golinko MS, Brem H, Tomic-Canic M. Perspective article: growth factors and cytokines in wound healing. Wound Repair Regen. 2008;16(5):585601.

25 Cao R, Bråkenhielm E, Pawliuk R, Wariaro D, Post MJ, Wahlberg E, et al. Angiogenic synergism, vascular stability and improvement of hind-limb ischemia by a combination of PDGF-BB and FGF-2. Nat Med. 2003;9(5): 604-13.

26 Zarei F, Soleimaninejad M. Role of growth factors and biomaterials in wound healing. Artif Cells Nanomed Biotechnol. 2018; 46(Suppl 1):906-11.
27 Kondo N, Hashimoto M, Takuwa T, Matsumoto S, Okumura Y, Hasegawa S. Treatment of bronchial fistula after extraplural pneumonectomy using flexible bronchoscopy with the administration of OK432, fibroblast growth factor basic and fibrin glue sealant. Gen Thorac Cardiovasc Surg. 2020 Dec; 68(12):1562-4.

28 Schmidt A, Ladage D, Schinköthe T, Klausmann U, Ulrichs C, Klinz FJ, et al. Basic fibroblast growth factor controls migration in human mesenchymal stem cells. Stem Cells. 2006;24(7):1750-8.

29 Zeng Y, Gao HZ, Zhang XB, Lin HH. Closure of bronchopleural fistula with mesenchymal stem cells: case report and brief literature review. Respiration. 2019;97(3):273-6.

30 Galderisi U, Giordano A. The gap between the physiological and therapeutic roles of mesenchymal stem cells. Med Res Rev. 2014;34(5): 1100-26.
31 Takaoka K, Inoue S, Ohira S. Central bronchopleural fistulas closed by bronchoscopic injection of absolute ethanol. Chest. 2002; 122(1):374-8.

32 Stratakos G, Zuccatosta L, Porfyridis I, Sediari M, Zisis C, Mariatou V, et al. Silver nitrate through flexible bronchoscope in the treatment of bronchopleural fistulae. J Thorac Cardiovasc Surg. 2009; 138(3):6037.

33 Shekar K, Foot C, Fraser J, Ziegenfuss M, Hopkins P, Windsor M. Bronchopleural fistula: an update for intensivists. J Crit Care. 2010;25(1):47-55.

34 Pierson DJ, Horton CA, Bates PW. Persistent bronchopleural air leak during mechanical ventilation: a review of 39 cases. Chest. 1986; 90(3):321-3.

35 Grose R, Dickson C. Fibroblast growth factor signaling in tumorigenesis. Cytokine Growth Factor Rev. 2005;16(2):179-86. 